\title{
Conduct Disorder and Its Relationship with Socio-Demographics Factors Among Secondary School Adolescents in Ondo State, Nigeria
}

\author{
Adeniyi V. Ojuope*, Opeyemi O. Ekundayo \\ Department of Psychology, Obafemi Awolowo University, Ile-Ife, Nigeria \\ Email address: \\ askadeniyi@gmail.com (A. V. Ojuope), ekundayoo@oauife.edu.ng (O. O. Ekundayo) \\ ${ }^{*}$ Corresponding author
}

\section{To cite this article:}

Adeniyi V. Ojuope, Opeyemi O. Ekundayo. Conduct Disorder and Its Relationship with Socio-Demographics Factors Among Secondary School Adolescents in Ondo State, Nigeria. Psychology and Behavioral Sciences. Vol. 9, No. 3, 2020, pp. 60-65. doi: 10.11648/j.ajap.20200903.12

Received: March 2, 2020; Accepted: March 16, 2020; Published: June 17, 2020

\begin{abstract}
The study investigated the prevalence of conduct disorder among secondary school adolescents and examined the relationship between socio-demographic factors (such as sex, age, school type, and family type) and conduct disorder among secondary school adolescents in Ondo State Nigeria. Primary data, sourced through the administration of questionnaire, were used in the study. The population for the study was the over 10,000 secondary school adolescents in Ondo State Nigeria. A sample of 420 was selected through a multistage sampling procedure using Cochran's sample size determination formula (385). The instrument used in collecting data for the study were the Conduct Disorder Scale - CDS and a section measuring the socio-demographic characteristics of the respondents. Collected data were subjected to descriptive and inferential statistics. Descriptive statistics was used to analyse the prevalence of conduct disorder, while correlational analysis was computed to draw inferences (showing existing relationships among the variables) on the population for the variables under study. Results showed a prevalence rate of $14.5 \%$ for conduct disorder among the secondary school adolescents in Ondo State, Nigeria. Results further showed a significant relationship between some sociodemographic variables and conduct disorder. The study concluded gender and type of school influence conduct disorder among secondary school adolescents in Ondo state, Nigeria.
\end{abstract}

Keywords: Conduct Disorder, Sex, Adolescence, Adjustment, Survey, Multistage Sampling Procedure

\section{Introduction}

Diagnostic and Statistical Manual of Mental Disorders (DSM-V) categorised conduct disorder (CD) as an antisocial behavior. The manual listed $\mathrm{CD}$ as part of the class of disorders labeled as "disruptive, impulse control and conduct disorders" which all encompass problems in the self-control of emotions and behaviour [5]. DSM-V defines and explains Conduct disorder as a repetitive and persistent pattern of behaviour in which the basic rights of others or major ageappropriate societal norms or rules are violated. It is manifested by the presence of at least three out of its 15 criteria in the past 12 months, with at least one criterion present in the past six months. These criteria include: aggression to people and animals, destruction of property, deceitfulness or theft, serious violations of rules, lack of remorse or guilt, callous/lack of empathy, unconcern about performance and shallow or deficient affect.

Conduct disorder appears to be a highly prevalent threat than expected [3]. A meta-analysis of epidemiological research estimates that the incidence of conduct disorder among children and adolescents aged 6-18 is 3.2 percent globally [7]. Furthermore, the incidence of conduct disorder seems to be relatively consistent across different race and ethnicity nations. Conduct disorder occurs in between two and 10 percent of the population, with a median prevalence rate of four percent $[5$, 22]. In Africa, it was reported that overall conduct disorder prevalence in Kenya was $31.4 \%$ [15]. In Nigeria, studies have documented a prevalence report of $15.82 \%$ in Port Harcourt [11]. Omotunde and Philomena reported a prevalence as high 
as $36 \%$ in Edo state [18] while Olasore et al, reported a prevalence of $56.5 \%$ in a study carried out in Aro, Abeokuta, Ogun state, among inmates that were within adolescence age [17].

Studies have suggested that conduct disorder is most rampant among children and adolescents $[5,16]$. Adolescence is a time inhuman life when many changes occur, and is characterised by some sporadic physical growth and physiological changes. It is also a period of cognitive, social, and contextual transitions [16]. This is the period young people mostly get enrolled in colleges and some into higher institutions. The adolescent period is a modern concept in the society leading to prolonged childhood, through lengthy adolescence as it is a time when the individual attends secondary school or learn a trade [2].

In Nigeria, even though studies have reported the prevalence of conduct disorder among adolescents, majority were carried out among adolescents in juvenile homes and correctional centres, while leaving a larger part of the adolescent population unstudied, and the few who showed interest in studying secondary school adolescents have significantly contributed to knowledge in documenting the influence conduct disorder have on learning [4, 19]. It is useful to report behavioural issues among the adolescent population in just one environment, but further studies should help address this knowledge gap by conducting such study among other subgroups of the adolescent population that have received insufficient research attention, such as adolescents in secondary school and potentially those out of college.

The global prevalence of conduct disorder ranged from $2 \%$ to $10 \%[5,7,22] 31.4 \%$ prevalence was reported in Kenya [15] and $15 \%$ to $56 \%$ in Nigeria $[11,18,17]$. There is need for more documentation in other states of Nigeria such as Ondo state where until this study, the prevalence of conduct disorder have not been documented. Furthermore, conduct disorder have been studied mostly among children adolescents having considered these (childhood and adolescence) as the basic onsets for conduct disorder $[5,16]$.

Developmentally there are two onsets for conduct disorder which are childhood and adolescence onsets. Individuals in the adolescence-onset pathway show an amplification of the normative process of adolescent rebellion. That is, most adolescents show some level of rebelliousness to parents and other authority figures [6]. This rebelliousness is part of a process by which the adolescent begins to develop his or her autonomous sense of self and his or her unique identity. The age factor of conduct disorder is however best expressed when the onset is put into consideration. A number of reviews of research support important differences between children who begin showing severe conduct problems and antisocial behaviour in childhood versus those whose onset of antisocial behaviour does not emerge until adolescence. It was reported that the prevalence of conduct disorder among adolescents is as high as $15.82 \%$ [12]. They studied 885 students with the age range of 9-18 years with a modal age of 13 years and found that 140 of them met the criteria for the diagnosis of conduct disorder. This report describes the presence of conduct disorder among adolescents, and submits that conduct disorder is not peculiar to adolescents in correctional centers only but that secondary school students aged 9-18 also meet the criteria for conduct disorder.

Children in the childhood-onset group often begin showing mild conduct problems (e.g., oppositional behaviour, temper tantrums) as early as pre-school or early elementary school, and their behavioural problems tend to intensify in rate and severity throughout childhood and into adolescence [14]. In contrast, Frick highlighted, the adolescent-onset group does not show significant behavioural problems in childhood, but they begin exhibiting significant antisocial and delinquent behaviour coinciding with the onset of adolescence. In addition to the different patterns of onset, the childhood-onset group is more likely to show aggressive behaviours in childhood and adolescence and is more likely to continue to show antisocial and criminal behaviour into adulthood. Childhood-onset conduct disorder seems to be more strongly associated to neuropsychological and cognitive deficits. Also, children who show the childhood-onset pattern seem to show more temperamental and personality risk factors, such as impulsivity, attention deficits, and problems in emotional regulation that could constitute conduct problems. This group also shows higher rates of family instability, more family conflict, and has parents who use less effective parenting strategies.

The prevalence of conduct disorder based on age seemed to increase with age and was statistically significant [15]. That is, the onset of conduct disorder tends to peak in late childhood and early adolescence with higher prevalence being observed in late adolescence. According to DSM-5 [5], as adolescents advance in age, they develop increased physical strength, cognitive abilities and sexual maturity, making them capable of more severe conduct problems such as rape or theft while confronting a victim. This was responsible for the higher conduct disorder prevalence rate for older adolescent, coupled with the less severe symptom behaviours such as lying and shoplifting which are the first to emerge at younger ages.

In their study Frank-Briggs and Alikor reported that sex distribution of adolescents with the conduct disorder was ratio 4 to 1 (male: 4 , female: 1) [12]. The various behaviours exhibited included bullying and or threatening classmates and other students, poor school attendance, stealing, and poor academic performance. Gender may be a possible contributing factor to conduct disorder, because most studies find that boys are more likely to show conduct disorder than girls. However, the degree of this difference may vary somewhat across developmental stages and possibly setting [14]. The different outcomes and risk factors for the two subtypes of antisocial individuals (male and female) may make children in the childhood-onset group develop their problem behaviour through a transactional process involving a difficult and vulnerable child (e.g., impulsive, with verbal deficits) who experiences an inadequate rearing environment (e.g., poor parental supervision, poor quality schools). This 
dysfunctional transactional process interrupts the child's socialization leading to poor social relations with persons both within (e.g., parents and siblings) and without (e.g., peers and teachers) the immediate family. These disruptions lead to enduring vulnerabilities that can negatively affect the child's psychosocial adjustment across the lifespan [14]. Gitonga, et al reported that conduct disorder prevalence was higher in male respondents $(36.5 \%)$ compared to female respondents $(26.7 \%)$, even though their study had more females than males, the difference was still significantly higher in male than in female adolescents [15].

Given the importance and incidence of conduct disorder among children and adolescents, it is not surprising that a substantial quantity of studies has concentrated on understanding its causes. Frick integrated risk factors such as prenatal development (exposure to toxins), early child care (bad quality child care), and more importantly family (ineffective discipline), peer (association with deviant colleagues) and neighbourhood (elevated levels of exposure to violence) as variables of influence. However, the prevalence of conduct disorder among secondary school

adolescents have not been reported in Ondo State Nigeria, where this study was carried out.

\section{Methodology}

\subsection{Sample Size and Sampling Technique}

Sample Size for the study was calculated using the Cochran's equation for representative sample for large proportions: $n_{0}=\frac{Z^{2} p q}{e^{2}}$

Where $\mathrm{n}_{0}$ is the sample size, $\mathrm{Z}^{2}$ is the abscissa of the normal curve that cuts off an area $\alpha$ at the tails ( $1-\alpha$ equals the desired confidence level is $95 \%$ ), e is the desired level of precision, $\mathrm{p}$ is the estimated proportion of an attribute that is present in the population, and $\mathrm{q}$ is $1-\mathrm{p}$. The value for $\mathrm{Z}$ is found in statistical tables which contain the area under the normal curve. Assume $\mathrm{p}=.5$ (maximum variability), Confidence level $=95 \%$, precision $= \pm 5 \%$ precision. The resulting sample size is $n_{0}=\frac{Z^{2} p q}{e^{2}}$

$$
n_{0}=\frac{Z^{2} p q}{e^{2}}=n_{0}=\frac{(1.96)^{2} \times 0.5 \times 0.5}{(0.05)^{2}}=384.16 \text { (rounded up to } 385 \text { individuals) }
$$

For the purpose of gathering enough data that will sufficiently represent the population and prevent shortcomings as a result of non-response or loss in the data collection process, four hundred and twenty (420) respondents were sampled for the study. The three senatorial districts in the state were sampled equally (140 sample from each).

Participants were selected through multi-stage sampling procedure. Ondo state has three Senatorial Districts which are; Ondo North Senatorial District, Ondo Central Senatorial District and Ondo South Senatorial District. In the first stage, one Local Government Area was randomly selected (through balloting) from each of the three Senatorial Districts in the State; Owo-Ose Local Government Area from Ondo North Senatorial District, Akure South Local Government Area from Ondo Central Senatorial District and Ile Oluji-Oke Igbo Local Government Area from Ondo South Senatorial District. In the second stage, one city (based on the number of schools) was purposively selected from each of the Local Government Areas; Owo from Owo-Ose Local Government Area, Akure from Akure South Local Government Area, and Ile Oluji from Ile Oluji-Oke Igbo Local Government Area. In the third stage, two secondary schools (one private and one public) were purposively selected from the cities based on the population of students: Methodist High School, Owo, and Ahmadiyya Secondary School, Owo, from Owo town; Calvary International College, Akure, and St. Peters Unity Secondary School, Akure, from Akure; Dynamic Secondary School, Ile Oluji and Gboluji (Anglican) Grammar School, from Ile Oluji,. In the fourth stage, one arm of JSS1-3 and SS1-3 were randomly selected from each of the schools. In the final stage, accidental sampling technique was used to select students present in class on the day of data collection; Methodist High School (73 respondents), Ahmadiyya
Secondary School (67 respondents), Calvary International College (69 respondents), St. Peters Unity Secondary School (71 respondents), Dynamic Secondary School (62 respondents), and Gboluji (Anglican) Grammar School (78 respondents).

\subsection{Research Instruments}

Primary data was used in the study. A structured questionnaire consisting two sections: Section A contained the demographic information, while section $B$ was a standardized scale which measured conduct disorder..

Demographic Information: This section includes sociodemographic information of respondents, such as: age, gender, class, family type and type of school.

Conduct Disorder Scale (CDS): The Conduct Disorder Scale used for this study was adapted from the Adjustment Disorder Scale (ADS) [16]. The ADS comprises of 48 items measuring from four areas of adjustment disorders, namely: depressed mood (feeling sad, experiencing lack of pleasure in the things one used to enjoy - 10 items), conduct disorders (behavioural problems such as fighting, vandalizing property 13 items), substance and alcohol abuse symptoms (including problems with family or friends, work or school - 13 items), and anxiety and disturbance of emotions (nervousness, worry, difficulty concentrating - 12 items). Responses to the items range from Never True (1), Rarely True (2), Sometimes True (3), Always True (4) and is scored directly giving a possible minimum score of 48 and a possible maximum score of 192. The ADS has a reliability coefficient of 0.97 (Cronbach alpha measure of internal consistency), and 0.82 (Guttman Split-Half coefficient). The section measuring conduct disorder was extracted for adaption. Three items were added to the subscale to enable the scale account for all the criteria listed for the 
diagnosis of conduct disorder. The result of this phase of the study provided the psychometric properties for this instrument (CDS).

Adaption and Standardisation of the Conduct Disorder Scale (CDS): The 13 items measuring conduct disorder were extracted and structured for this phase of the research, the structured scale finally comprise of 16 items measuring the five criteria for conduct disorder as defined by the Diagnostic and Statistical Manual of Mental Disorders Fifth Edition (DSM-V). The scale had five (5) items measuring aggression to people and animals, four (4) measuring destruction of property, three (3) measuring deceitfulness or theft, two (2) measuring serious violations of rules and two (2) measuring lack of remorse or guilt (callous-lack of empathy, unconcerned about performance and shallow or deficient affect). The possible minimum score is 16 and the possible maximum score is 64 . Statistic of one standard deviation above and below the mean $(x \pm S D)$ was used to categorise the respondents into groups of conduct disorder. Higher scores than the mean plus the standard deviation $(\mathrm{X}+\mathrm{SD})$ indicate a severe manifestation of conduct disorder, lower scores than the mean minus standard deviation (X - SD) indicates minimal level, while scores between severe and minimal levels indicate moderate manifestation of conduct disorder. The results of this phase of the study provide the psychometric properties for this instrument (CDS). The Crombach Alpha coefficient is 0.65 while a correlation matrix was computed to determine a discriminant validity value (0.14) using the Physical Abuse Inventory by Fakunmoju \& Bammeke (2013) ( $\mathrm{r}=-0.21$, $\mathrm{p}>.05)$. Four hundred and twenty questionnaires were distributed in equal proportions across the three senatorial districts within the state.

\subsection{Data Analysis}

The data collected in this study were subjected to descriptive and inferential statistical analysis. Descriptive statistics (such as frequency counts percentages, mean and standard deviation) were used in analysing the sociodemographic variables, and in analysing the prevalence of conduct disorder among the population. Inferential statistics was used in analysing the objective that sought to examine the relationships between socio-demographic characteristics of the respondents and conduct disorder.

\section{Results}

The Socio-Demographic Information of the Participants was computed and presented in Table 1.

Table 1. Socio-Demographic Characteristics of participants.

\begin{tabular}{lll}
\hline Variable & $\mathbf{n}$ & $\mathbf{\%}$ \\
\hline Class & & \\
JSS1 & 26 & 6.6 \\
JSS2 & 71 & 18.1 \\
JSS3 & 40 & 10.2 \\
SSS1 & 41 & 10.5 \\
SSS2 & 97 & 24.7 \\
SSS3 & 117 & 29.8 \\
\hline
\end{tabular}

\begin{tabular}{lll}
\hline Variable & $\mathbf{n}$ & $\mathbf{\%}$ \\
\hline Total & 392 & 100 \\
Age (years) & & \\
$11-13$ & 154 & 39.2 \\
$14-16$ & 188 & 48 \\
$17-19$ & 50 & 12.8 \\
Total & 392 & 100 \\
Gender & & \\
Male & 210 & 53.6 \\
Female & 182 & 46.4 \\
Total & 392 & 100 \\
Family Type & & \\
With Parents & 383 & 97.7 \\
Orphans & 9 & 2.3 \\
Total & 392 & 100 \\
School Type & & \\
Private & 153 & 39.0 \\
Public & 239 & 61.0 \\
Total & 392 & 100 \\
\hline
\end{tabular}

Note. $\mathrm{n}=$ population of sample; $\%=$ percentage of population;

Table 1 presents the socio-demographic characteristics of the respondents. The table revealed that $26(6.6 \%)$ respondents were in JSS1, $71(18.1 \%)$ in JSS2 and 40 $(10.2 \%)$ in JSS3. Also, $41(10.5 \%)$ of the respondents were in SSS1, 97 (24.7\%) and 117 (29.8\%) in SSS2 and SSS3 respectively. Table 1 also showed that all the respondents fall between ages 11 and 19 years, which was the age range proposed for the study. Table 1 showed that $53.6 \%$ of the respondents were males while $46.4 \%$ were females; $81.1 \%$ of the respondents were from nuclear family, $16.6 \%$ from extended family and $2.3 \%$ from orphanage homes. The table also revealed that $39 \%$ were private school students and $61 \%$ were public school students.

Analysis of Objectives

The first objective was to investigate the prevalence of conduct disorder among secondary school adolescents in Ondo State Nigeris. A two-stage procedure was employed to achieve this objective. In the first stage, the statistic of one standard deviation above and below the mean $(x \pm \mathrm{SD})$ was used to categorise the respondents into groups of conduct disorder. The scores of the respondents on conduct disorder ranged between 16 and 61 with a mean of 28.67 and a standard deviation of 7.63. Therefore one standard deviation above the mean was $28.67+7.63=36.3$ (approximated to a score of 36) and one standard deviation below the mean was $28.67-7.63=21.04$ (approximated to a score of 21 ). Thus, respondents with the scores in the range of 16 to 21 were categorised as having minimal level of conduct disorder (that is, those who whose conduct is healthy to themselves and the society), those with scores in the range of 22 to 36 as having moderate level of conduct disorder (that is, those who rarely manifest conduct disorder, for example: one criterion of conduct disorder in a year), and those with scores in the range of 37 to 61 as having severe level of conduct disorder (that is, those who often exhibit behaviour that meet the diagnostic criteria of conduct disorder). Simple frequency counts and percentages were then carried out to determine the number of participants in each category with their percentages. The result of this analysis is presented in Table 
Table 2. Summary of frequency, percentages, mean, and standard deviation showing the prevalence of conduct disorder among the population of study.

\begin{tabular}{llll}
\hline Category & Score Range & Frequency & Percent \\
\hline Minimal & $16-21$ & 71 & 18.1 \\
Moderate & $22-36$ & 264 & 67.3 \\
Severe & $37-61$ & 57 & 14.5 \\
& Total & 392 & 100 \\
\hline
\end{tabular}

Table 2 shows that $71(18.1 \%)$ of the population reported minimal level of conduct disorder, $264(67.3 \%)$ reported moderate in conduct disorder and $57(14.5 \%)$ of the sampled population reported severe level of conduct disorder.

The second objective of the study was to examine the relationships between socio-demographic factors and conduct disorder among secondary school adolescents in Ondo State Nigeria. To analyse this objective a correlation analysis was computed and the results are shown in Table 3.

Table 3. Summary of multiple correlation showing the relationship between class, age, family type, gender, school type and conduct disorder (CD).

\begin{tabular}{llllllll}
\hline & Variables & $\mathbf{1}$ & $\mathbf{2}$ & $\mathbf{3}$ & $\mathbf{4}$ & $\mathbf{5}$ & $\mathbf{6}$ \\
\hline 1 & CD & - & & & & & \\
2 & Class & -0.07 & - & & & & \\
3 & Age & 0.08 & $0.75^{* *}$ & - & & & \\
4 & Family & 0.07 & -0.02 & 0.09 & - & & \\
5 & Gender & $0.21 * *$ & 0.05 & $-0.13^{*}$ & -0.08 & - & \\
6 & School & $0.13 * *$ & $-0.26^{* *}$ & -0.18 & $0.18^{* *}$ & -0.08 & - \\
\hline
\end{tabular}

Note: **Correlation is Significant at the 0.01 level (two-tailed)

* Correlation is Significant at the 0.05 level (two-tailed)

$\mathrm{N}=392$

The results in Table 3 shows that the class $(r=-0.07)$, age $(\mathrm{r}=0.08)$, and family type $(\mathrm{r}=0.07)$ of secondary school adolescents in Ondo state do not have a significant relationship with conduct disorder, however, gender had a significant positive relationship with conduct disorder $(\mathrm{r}=$ 0.21 ), while school type also has a significant positive relationship with conduct disorder $(\mathrm{r}=0.13)$ among secondary school adolescents within the state. The implications of these results are that class, age and family type does not determine whether an adolescent will manifest conduct disorder or not. However, the results reveal that the gender (male and female) of the study population correlates with their exhibition of conduct problems. Results further indicate that type of school (private or public) has strong relationship with their manifestation of conduct disorder.

\section{Discussions}

The study revealed that $14.5 \%$ of secondary school adolescents in Ondo State manifest conduct disorder. The implication of this finding is that, of every 1000 adolescents who are in school, 145 of them manifest high (severe) level of conduct disorder. In other words, 145 adolescents of every 1000 have strong tendencies for armed robbery, hooliganism, occultism, and etcetera in the nearest future if they are not attended to early enough by councillors, therapists and other concerned agencies [18]. This finding corroborates the prevalence report of $15.82 \%$ submitted by Fank-Briggs and Alikor [11]. This finding also supports the work of Gitonga, et al [15] who reported that overall conduct disorder prevalence in Kenya was as high $31.4 \%$, and Sainsbury Centre for Mental Health [21] also reported a prevalence of $30 \%$ in London, United Kingdom. This finding is similar to the prevalence reported by Olashore, et al [17] that the prevalence of conduct disorder is 56.5\% Aro, Abeokuta, Nigeria. Omotunde and Philomena [18] also reported a prevalence of $36 \%$ in Edo State Nigeria.

The finding is lower compared to other studies that have been mentioned above $[15,17,18]$ this may be due to the fact that their study was done in correctional centres and juvenile homes, with a population whose circumstances and other environmental factors may have influenced, compared to secondary school adolescents, who are often exposed to societal norms and moral standards by parents, teachers or school councillors. Also, this finding corroborates the documented global prevalence of $2 \%-10 \%$ [5, 22, 7] among adolescents.

Furthermore, variables such as, gender and type of school, were found to be significantly associated with conduct disorder. This finding supports the report of Rogo and Garba [20] and Diwe, Aguocha, Duru, Uwakwe, Merenu and Nwefoh [9] who reported that there is significant gender difference in the rate and pattern of conduct disorder among senior secondary school students (among which majority are adolescents) of Dala education zone, Kano State-Nigeria. Furthermore, Adeusi [1] reported a partial relationship between socio-demographic factor (socio-economy) and conduct disorder (aggressive behaviour). Even though none of these studies reported any relationship between sociodemographic variables such as school type, this study have enriched the body of knowledge on the relationship between socio-demographic variables and conduct disorder.

\section{Conclusion}

This research has documented the prevalence and assessment of conduct disorder among secondary school adolescents. The study showed a slightly high prevalence of conduct disorder among secondary school adolescents. This means that adolescence can be a difficult time indeed. The study further concludes that socio-demographic factors such as gender and type of school are strongly related to conduct disorder among secondary school adolescents in Ondo State, Nigeria.

\section{Recommendations}

The study therefore recommends that the Ondo State Government and other concerned agencies in Nigeria, saddled with the responsibility of children affairs and development should pay closer attention to secondary school adolescents specifically those in public schools.

Further studies are encouraged to attempt investigations 
into whether conduct disorder among children and adolescents- which literature have documented to be associated with future social vices and other criminal acts - is associated with cyber-security problems.

\section{References}

[1] Adeusi, S. O. (2017). Parenting and demographic factors as predictors of adolescent conduct disorder: efficacy of multimodal intervention. Gender and Behaviour, 15 (1), 82178230 .

[2] Agiobu-Kemmer, I. (2009). A model of the total human lifespan. In Agiobu-Kemmer (Ed): Growing Up: Theories and Stories. Lagos: Springfield Books

[3] Akinola, A. N. (2014). Bibliotherapy as an Alternative Approach to Children's Emotional Disorders. Creative Education, 05 (14), 1281-1285.

[4] Aladegbola, A. G. (2013). Oppositional Defiant and Conduct Disorder in Ekiti State Secondary Schools, the effect on learning. Global Advanced Research Journal of Educational Research and Review. 2 (11) 218-221. (ISSN: 2315-5132)

[5] American Psychiatric Association. (2013). Diagnostic and statistical manual of mental disorders (DSM-5®). American Psychiatric Pub.

[6] Brezina, T., \& Piquero, A. R. (2007). Moral beliefs, isolation from peers, and abstention from delinquency. Deviant Behavior, 28 (5), 433-465.

[7] Canino, G., Polanczyk, G., Bauermeister, J. J., Rohde, L. A., \& Frick, P. J. (2010). Does the prevalence of CD and ODD vary across cultures? Social psychiatry and psychiatric epidemiology, 45 (7), 695-704.

[8] Cochran, W. G. (1963). Sampling Techniques, 2nd Ed., New York: John Wiley and Sons, Inc.

[9] Diwe, K., Aguocha, C., Duru, C., Uwakwe, K., Merenu, A., \& Nwefoh, E. (2016). Gender Differences in Prevalence and Pattern of Conduct Disorder among Adolescent Secondary School Students in South East Nigeria. Asian Journal of Social Sciences \& Humanities Vol, 5,1 .

[10] Fakunmoju, S. B., \& Bammeke, F. O. (2013). Development of perception of child maltreatment scale: Reliability and validity analyses. Sage open, 3 (2), 2158244013490703.

[11] Frank-Briggs, A. I., \& Alikor, E. A. (2008). Conduct disorder amongst children in an urban school in Nigeria. Nigerian
Health Journal, 8 (3-4), 44-47.

[12] Frank-Briggs, A. I., \& Alikor, E. A. D. (2010). Anxiety disorder amongst secondary school children in an urban city in Nigeria. International journal of biomedical science: IJBS, 6 (3), 246

[13] Frick, P. J. (2004). Developmental pathways to conduct disorder: Implications for serving youth who show severe aggressive and antisocial behavior. Psychology in the Schools, $41(8), 823-834$.

[14] Frick, P. J. (2016). Current research on conduct disorder in children and adolescents. South African Journal of Psychology, 46 (2), 160-174.

[15] Gitonga, M., Muriungi, S., Ongaro, K., \& Omondi, M. (2017). Prevalence of Conduct Disorder among Adolescents in Secondary Schools: A Case of Kamukunji and Olympic Mixed Sub-County Secondary Schools in Nairobi County, Kenya. African Journal of Clinical Psychology, 1, 85-101.

[16] Israel, U. N. (2016). Assessment of Adjustment Disorders, Parental Rejection and their Correlates among some Adolescents in Lagos Metropolis, Nigeria. (PH.D), University of Lagos.

[17] Olashore, A. A., Ogunwale, A., \& Adebowale, T. O. (2016). Correlates of conduct disorder among inmates of a Nigerian Borstal Institution. Child and adolescent psychiatry and mental health, 10 (1), 13.

[18] Omotunde, E. E., \& Philomena, O. (2014). Prevalence of conduct disorder among adolescents in a senior secondary school in Benin City, Edo State, Nigeria. International Journal of Pedagogy, Policy and ICT in Education, 4 (1), 1528.

[19] Osagie-Obazee, G. E., \& Eduwen, F. O. (2016). The influence of family factors on delinquent adolescents in secondary schools in Edo South Senatorial District of Edo State. AFRREV IJAH: An International Journal of Arts and Humanities, 5 (3), 231-243.

[20] Rogo, I. S., \& Garba, A. M. (2018). Gender Difference in the Prevalence and Pattern of Conduct Disorder Among Adolescent Students of Senior Secondary Schools in Dala Education Zone, Kano State-Nigeria. Journal of Teaching and Teacher Education, 6 (01), 35-45.

[21] Sainsbury, C. M. H. (2009). Preventing early conduct problems and reducing crime. 134-138 Borough High Street, London SE1 1LB.

[22] Scott, S. (2007). Conduct disorders in children. BMJ: British Medical Journal, 334 (7595), 646. 